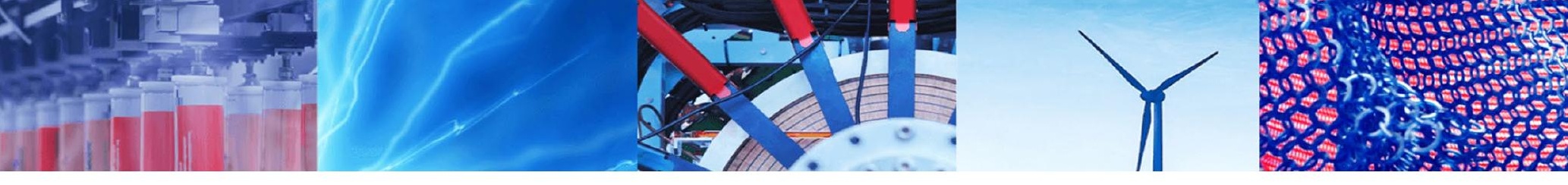

Research Article

\title{
Analysis of the influence of the seat foam density in the posture of hemiplegic wheelchair users using computerized photogrammetry
}

\author{
Caroline L. G. de Abreu ${ }^{1}$ - Eduardo L. M. Naves ${ }^{1}$. Angela A. R. de Sá ${ }^{1}$ (D) Deny Gomes de Freitas ${ }^{1}$
}

Received: 13 May 2020 / Accepted: 1 October 2020 / Published online: 11 October 2020

(c) Springer Nature Switzerland AG 2020

\begin{abstract}
The use of a wheelchair after a stroke is often necessary, and this device can assist in support and proper positioning in sitting posture. However, there is not much scientific evidence proving the benefits of adaptations in wheelchairs for individuals with a motor and sensory impairments, mainly those with hemiplegia. The aim of this study is to assess whether adaptation with foam of different densities is effective in improving the sitting posture of hemiplegic wheelchair users. The study was carried out on 18 participants (seven female and eleven male), hemiplegics, wheelchair users and with an average age $=61$. The computerized photogrammetry technique was used to analyze the posture of the participants sitting in foams of different densities. In order to perform the statistical analysis, the Shapiro-Wilk hypothesis test was used to assess the normality of the data. The results highlight the improvement not only in pelvic alignment, but also the trunk and head using different combinations of density foam seats. In addition, the results suggest that the use of densities $33 \mathrm{~kg} / \mathrm{m}^{3}$ and $40 \mathrm{~kg} / \mathrm{m}^{3}$ is sufficient to have a better body alignment.
\end{abstract}

Keywords Seating $\cdot$ Sitting posture $\cdot$ Hemiplegia

\section{Introduction}

The use of a wheelchair may be essential in the process of rehabilitation of individuals with neurological impairment. This equipment can be considered an orthotic device for sitting posture, as its use promotes user comfort (pressure relief and body support) and can increase the individual's performance and quality of life.[1]. However, in many cases, depending on the user's needs, some adjustments in the wheelchair seat are required. This process requires the use of specific equipment and knowledge in different areas and, mainly, in the biomechanical concepts of sitting posture. An adequate sitting posture for people with poor postural control can prevent the worsening of the clinical condition and prevent motor deficits $[2,3]$.

Individuals with hemiplegia due to a cerebrovascular accident (CVA) usually need some posture adjustment.
Hemiplegia has as a consequence a lower control of the trunk and less automatic postural control. Thus, these people seek compensatory strategies to maintain stability, such as slipping in the wheelchair seat, sitting asymmetrically and seeking support in one of the two arms $[4,5]$.

The studies by Genthon et al. and Pelmutter et al. $[6,7]$ showed that the sitting posture of hemiplegic individuals is quite asymmetric. In these studies, they found greater displacement of the center of pressure of the hemiplegic individuals, when compared to a healthy group. Moreover, some studies have evaluated the efficiency of different foams to compensate for the adverse effects of poor sitting posture [8-10]. The results showed significant differences in the alignment and distribution of weight in the sitting posture of individuals with motor deficits when compared with healthy individuals. Also, the seats where

Angela A. R. de Sá, angelaabreu@gmail.com | ${ }^{1}$ Assistive Technology Group, Faculty of Electrical Engineering, Federal University of Uberlândia, Av Joao Naves de Avila, 2160-Bloco 3N, Uberlandia, Brazil. 
these individuals sit, whether of foam, water or air, can cause postural changes.

In addition, there are several studies in the literature regarding the sitting posture of children with cerebral palsy and adults with spinal cord injury, but there are not many researches with the focus on the population with sequels resulting from CVA [11]. Also, the lack of scientific evidence in the prescription of wheelchair adaptations implies the use of different combinations of foam densities in the manufacture of seats/backs. The use of different types of materials associated with foams emphasizes the need for studies to evaluate the effectiveness of the current methodology used.

Thus, the aim of this study is to evaluate whether the use of foam of different densities is effective in optimizing the sitting posture of hemiplegic wheelchair users. Our hypothesis is that the use of seats with different foam densities is able to improve the postural alignment of individuals with hemiplegia. This study has as scientific contribution the construction of evidence to support, or not, the effectiveness of these types of seats that are being widely used in clinical practice.

\section{Materials and methods}

This research was approved by the Research Ethics Committee of the Association for Assistance to Disabled Children (AADC) Protocol Number 01/2011. The study was conducted at AADC.

\subsection{Sample selection}

The sample selection began with the screening of 53 medical records of patients diagnosed with hemiplegia or CVA. These patients were in treatment at AADC or were on the waiting list to initiate the rehabilitation therapy.

The inclusion criteria were: a) Diagnosis of hemiplegia; b) Ability to maintain the sitting posture without support; c) Understanding simple orders; d) Use of wheelchair for home mobility and/or for long distances. The exclusion criteria were: a) Presence of musculoskeletal deformities; $b$ ) Diagnosis of hemiplegia due to other etiologies than CVA.

From those 53 pre-selected medical records, the following patients were excluded: A) Six patients: with diagnosis of hemiplegia due to other etiologies than CVA; $b$ ) One patient: with musculoskeletal deformities; c) Seven patients: they presented impaired comprehension; d) 14 patients: they were walking at home without wheelchair; e) Seven patients: they did not accept to participate in the research. Thus, a total of 18 individuals participated in this study.

\section{SN Applied Sciences}

\subsection{Experimental procedure}

The following steps were performed: a) Demarcation of anatomical points; b) Photographic records; c) Image analysis; d) Statistical analysis.

\subsubsection{Demarcation of anatomical points}

The procedure for demarcation of anatomical points was performed by an experienced occupational therapist. Initially, the therapist asked participants to remove their upper body clothes and tie their hair in a cap. The female participants were wearing a bikini.

To locate the anatomical points, on bare skin, the therapist used visual analysis and palpation. And also, to minimize errors, easy anatomical points of location and accuracy were chosen: head and trunk region. According to [12], the ability to palpate spinal levels is a basic skill and a pre-requisite to more complex palpatory tasks. In addition, the study of [13] found that the levels of palpation accuracy may be argued as clinically acceptable for noninvasive therapeutic intervention. Overall, according to [14], manipulative physiotherapists can reliably palpate nominated lumbar spinal levels and suggested that further training in spinal therapy enhances the palpatory skills of physiotherapists in palpating nominated lumbar spinal levels.

The anatomical points of the anterior frontal plane were demarcated with the participants sitting in their own wheelchairs so that they were more comfortable. Then each participant was invited to sit in the center of a backless wooden bench $(1.80 \mathrm{~m} \times 0.80 \mathrm{~m} \times 0.45 \mathrm{~m})$ so that the anatomical points of the posterior frontal plane were demarcated. The landmarks were placed only once.

To demarcate the anatomical points, a double-sided tape and styrofoam spheres of $1.5 \mathrm{~cm}$ in diameter were used as landmarks. For each participant, seven anatomical points were demarcated in the anterior frontal plane (Fig. 1) and 10 points in the posterior frontal plane (Fig. 2). From these landmarks, eleven angles were established: they were formed using the segment line between two landmarks and the X-or Y-axis (Figs. 1 and 2).

\subsubsection{Photographic records}

After the procedure of demarcation of the anatomical points, each participant was photographed eight times: four records of the posterior frontal plane and four of the anterior frontal plane. The participants' feet remained on 


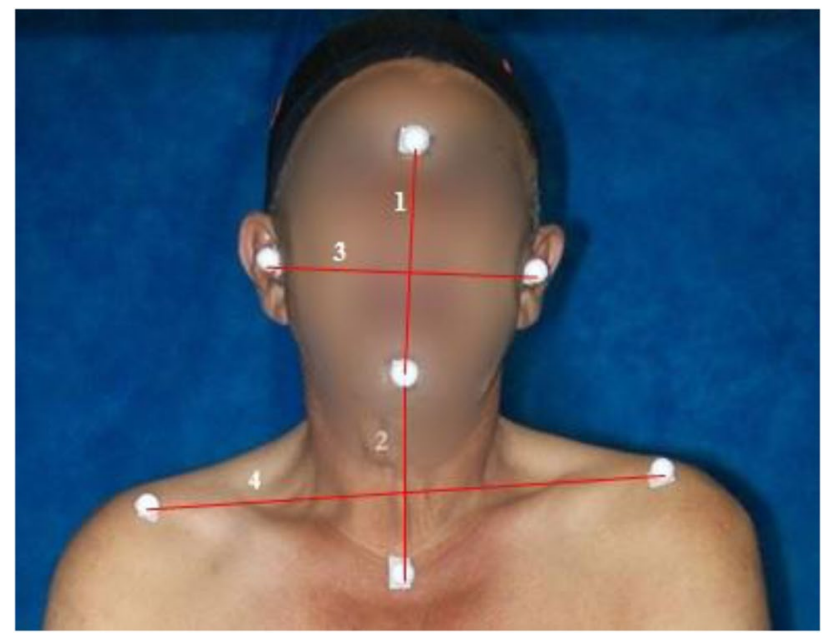

Fig. 1 Angles of the anterior frontal plane: 1) GMY_angle formed between the segment line [glabella-mental protuberance] and Y-axis, 2) MMY - angle formed between the segment line [mental protuberance-manubriosternal joint] and Y-axis, 3) TTX-angle formed between the segment line [left tragion-right tragion] and $X$-axis, 4) AAX - angle formed between the segment line [left acromion point -right acromion point] and $\mathrm{X}$-axis

the ground, and when necessary, a wooden support was used for proper positioning of the feet.

We used two digital cameras for the records. For the photographic recording of the posterior front plane, the first camera was positioned parallel to the ground, on a tripod, at a height of $0.95 \mathrm{~m}$ and the center of the camera lens was $1.10 \mathrm{~m}$ from the rear edge of the seat. And we used the second camera for the photographic recording of the anterior front plane: the center of the camera lens was positioned $0.80 \mathrm{~m}$ from the anterior edge of the seat, also parallel to the ground, on a tripod at the same height of $0.95 \mathrm{~m}$ (Fig. 3). The zoom features of the cameras were not used. So these measures were established for a better recording of the anatomical points that were demarcated. And the photographic records of the frontal plane (anterior and posterior) were taken almost simultaneously, triggering one camera and then the other.

The first record was with the individual seated on the backless wooden bench without a foam seat-we will call it the initial situation A0. Then, the individual was photographed seated on three types of seats: A1 (foam density $33 \mathrm{~kg} / \mathrm{m}^{3}$ ), A2 (part with foam density $33 \mathrm{~kg} / \mathrm{m}^{3}$ and the other part with foam density $40 \mathrm{~kg} / \mathrm{m}^{3}$ ) and A3 (part with foam density $33 \mathrm{~kg} / \mathrm{m}^{3}$ and the other part with foam density $40 \mathrm{~kg} /$ $\mathrm{m}^{3}$ intercalated with two layers of ethyl vinyl acetate-EVA), as shown in Fig. 4. The sequence for placing the seats was randomly chosen for each individual. For each seat change, 1 min was waited for the next photographic record. As soon as the seat was replaced, a single verbal

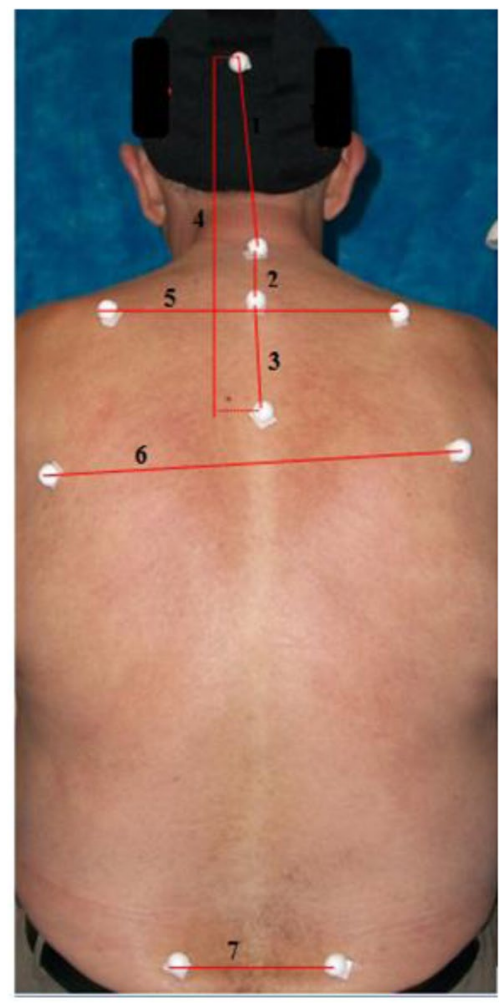

Fig. 2 Angles of the posterior frontal plane: 1) OC7Y-angle formed between the segment line [occipital protuberance-C7 spinous process] and $Y$-axis, 2) C7T3Y-angle formed between the segment line [C7 spinous process-T3 spinous process] and $\mathrm{Y}$-axis, 3) T7T3Y - angle formed between the segment line [T7 spinous process-T3 spinous process] and Y-axis, 4) OT7Y-angle formed between the segment line [occipital protuberance-T7 spinous process] and Y-axis, 5) MSMSX-angle formed between the segment line [medial border of left spine of the scapula-medial border of right spine of the scapula] and X-axis, 6) ISISX —angle formed between the segment line [inferior angle of left scapula-inferior angle of right scapula] and X-axis, 7) LIRIX_angle formed between the segment line [left posterior superior iliac spine-right posterior superior iliac spine] and $\mathrm{X}$-axis

command was given to the individual: "keep your eyes on the camera in front of you."

For seats $A 2$ and $A 3$, the pelvic obliquity was identified through the visual and palpatory evaluation (performed in the initial situation $\mathrm{A} 0$ ) to choose the side on which the seat would be positioned. Thus, according to this clinical evaluation, the foam side with a density other than $33 \mathrm{~kg} /$ $\mathrm{m}^{3}$ was placed under the hemibody that was receiving the highest weight discharge.

\subsubsection{Image analysis}

The photographic records were analyzed using the software CorporisPro ${ }^{\circledR}[15]$. This is a computerized photogrammetry software for biomechanical and postural studies. 
Fig. 3 Positioning of the participant and the cameras for the photographic record of the front plane (anterior and posterior)

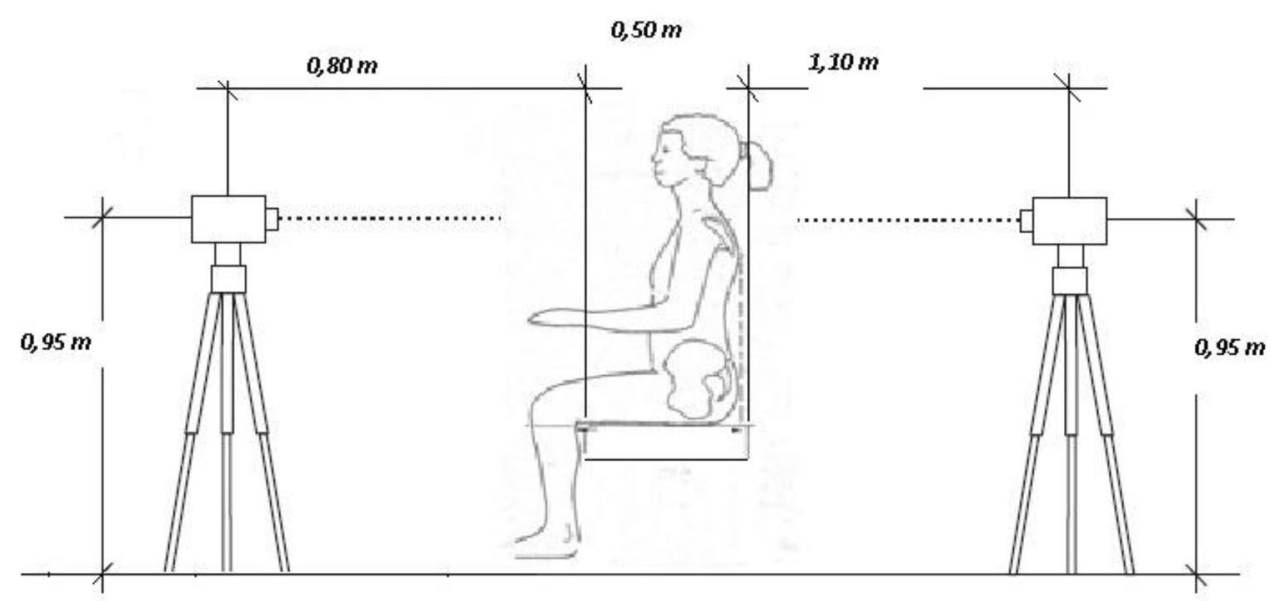

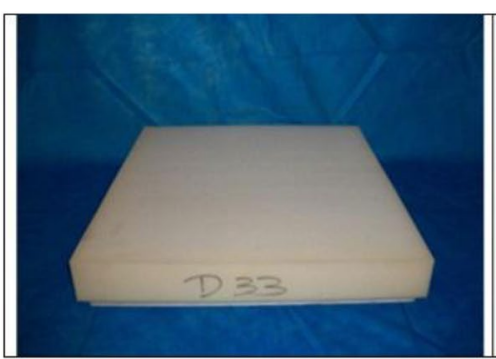

(a)

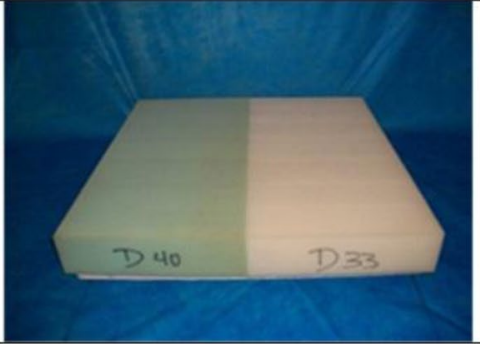

(b)

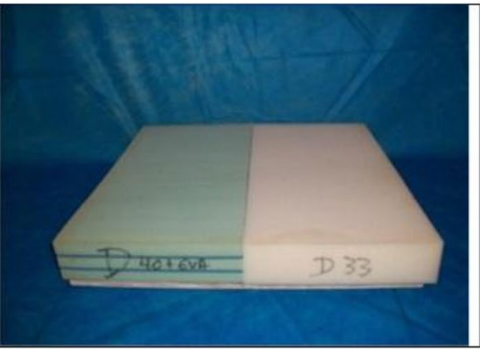

(c)
Fig. 4 Configurations of the evaluated seats: a A1-foam density $33 \mathrm{~kg} / \mathrm{m}^{3}$, b A2 - part with foam density $33 \mathrm{~kg} / \mathrm{m}^{3}$ and the other part with foam density $40 \mathrm{~kg} / \mathrm{m}^{3}$, c A3-part with foam density

For each individual, the analysis of the images was as follows: 1) Uploading the four photos of the anterior frontal plane and the four photos of the posterior frontal plane; 2) Identification of two points to establish the vertical axis and, automatically, the software delimits the horizontal line; 3) Manual identification of landmarks, 4) Manual selection of markers to establish angles; 5) The software performs the angle measurements.

The angles calculated by the CorporisPro software may have positive or negative values. For the angles drawn with vertical reference, will be positive those who are to the right of this line-which will suggest the body inclination on the right. And the angles that are to the left of that line will be negative-suggesting body inclination on the left. And for angles drawn with the horizontal line, those that are below that line will have negative values-indicating an inclination of the body to the right. And those angles above this line will be positive-suggesting an inclination of the body to the left (Fig. 5).
$33 \mathrm{~kg} / \mathrm{m}^{3}$ and the other part with foam density $40 \mathrm{~kg} / \mathrm{m}^{3}$ intercalated with two layers of ethyl vinyl acetate (EVA)
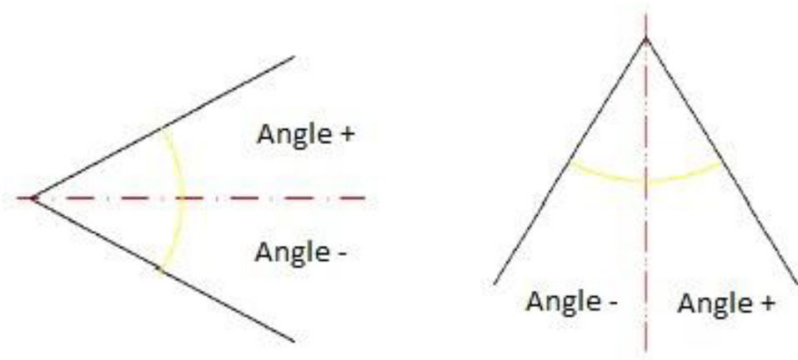

Fig. 5 Angle orientation in CorporisPro software

\subsubsection{Statistical analysis}

We performed descriptive statistics because a complete and accurate description of the data can be useful for inferences about the original population of the sample [16]. The variables gender, age, motor sequel and pelvic obliquity were described in terms of frequency and percentage values.

\section{SN Applied Sciences}


For the variables resulting from the angle measurements, the following statistical calculations were performed: mean, median, standard deviation and the boxplot chart. The box-plot chart makes it possible to identify outliers or compare the dispersion of different data sets [17]

Shapiro-Wilk test was performed to assess the normality of the data [18]. After finding that the hypothesis of normality could not be assumed for all data sets, we chose to normalize the data. This choice was based on the assumption that parametric tests are more robust than nonparametric tests [19]. Thus, the Box-Cox transformation was applied to normalize the data. This method uses the calculation of the minimum values of asymmetry and kurtosis of samples to achieve normality [20]

After the data normalization, paired T test was used to compare whether the mean of each data set changed after participants' seats were replaced. According to [21], the paired $T$ test can be used in studies where a single group of participants is evaluated before and after an event/ intervention.

\section{Results}

Table 1 shows the descriptive statistics of the sample: average age of: 63.33 years, seven female and eleven male. Regarding the sequel, $50 \%$ of the participants had right hemiparesis and the other half had left hemiparesis. And according to the photogrammetric analysis performed in the initial position $\mathrm{A} 0,55.55 \%$ of the participants presented pelvic obliquity for the left side and $44.44 \%$ presented it for the right side.

In addition, the descriptive analysis indicated divergences between the clinical evaluation and the results obtained through computerized photogrammetry in the evaluation of the pelvic obliquity of 4 participants.

Table 1 Descriptive statistics of the participants: gender, average age, hemiparesis (right and left) and pelvic obliquity (right and left)

\begin{tabular}{|c|c|c|}
\hline \multicolumn{3}{|l|}{ Data of the participants } \\
\hline & $\begin{array}{l}\text { Quantity of par- } \\
\text { ticipants }\end{array}$ & Percentage \\
\hline Total quantity of participants & 18 & $100 \%$ \\
\hline Male & 11 & $61.11 \%$ \\
\hline Female & 7 & $38.88 \%$ \\
\hline Average age & 63.33 & \\
\hline Hemiparesis $\mathrm{R}$ & 9 & $50 \%$ \\
\hline Hemiparesis L & 9 & $50 \%$ \\
\hline Pelvic obliquity $\mathrm{R}$ & 8 & $44.44 \%$ \\
\hline Pelvic obliquity L & 10 & $55.55 \%$ \\
\hline
\end{tabular}

However, in these 4 specific cases, the values were close to zero $\left(-0.2^{\circ} ; 0.6^{\circ} ; 0.6^{\circ} ; 0.8^{\circ}\right)$-which indicates a pelvic alignment close to the ideal.

Regarding postural alignment in the initial situation (A0), the data indicate a significant misalignment of the angles evaluated, presenting an average greater than $3^{\circ}$ for all 11 angles (Fig. 6)

Through the analysis of the mean and median values of the angles, we observed that in seven angles the smallest values were found in the $\mathrm{A} 2$ seat configuration. This finding suggests that the values found during the use of the A2 seat are closer to the value of zero. So, it was adopted as an indicator of postural alignment for this work.

Moreover, the descriptive analysis using box-plot graphs for each angle $x$ seat configurations, point to a variation of values in the different seat configurations when compared to the initial situation A0 (Fig. 7). The A3 seat configuration showed the highest values at six angles of the 11 angles evaluated. Another important remark is that the tendency of the values in A2 to be lower than in other seat configurations was also verified in this analysis of the box-plot graphs.

The paired t test was applied to each of the 11 angles evaluated in the anterior and posterior frontal plane. For each angle, we analyzed the following seat configuration pairs: $A 0 \times A 1 ; A 0 \times A 2 ; A 0 \times A 3, A 1 \times A 2, A 1 \times A 3$ and $A 2 \times A 3$. The paired t test indicates whether there is a statistically significant difference $(p<0.05)$ between the mean values of two data sets. In cases where the difference was verified, we modified the alternative hypothesis and applied the paired t test again to establish the data set with the highest or lowest value. Table 2 presents the values $p$ of the paired t test. For pairs in

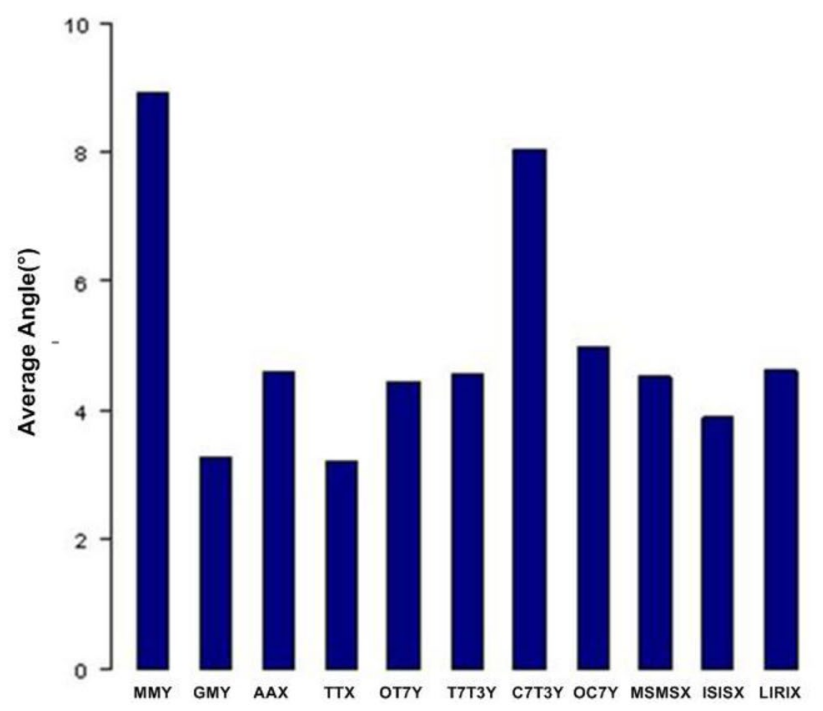

Fig. 6 Average angle-initial situation (A0) 


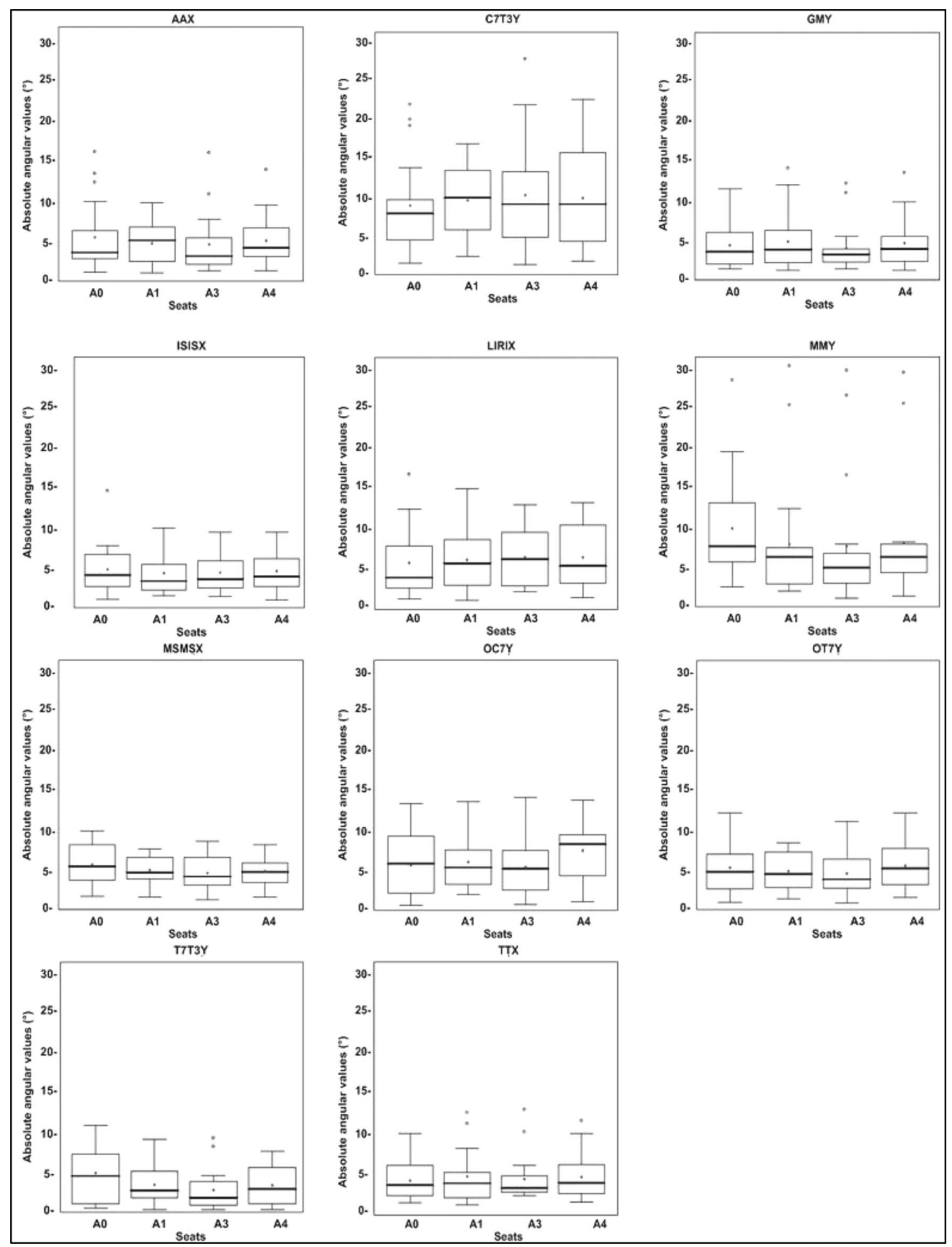

Fig. 7 Box-plot Graph: absolute angular values $x$ seat configurations

which the similarity hypothesis was rejected $(P<0.05)$, Table 2 shows the value of the second test and indicates whether the data set is greater $\left(^{*}\right)$ or smaller $\left(^{* *}\right)$ than the second set paired data.
Furthermore, we verified five pairs in which the initial situation (A0) demonstrated greater alignment than the other seat configurations: $\mathrm{A} 0 \times \mathrm{A} 2$ and two for each pairing of $A 0 \times A 1$ and $A 0 \times A 3$. Also, in two other pairing, $A 0$ was 
Table $2 p$ values for each pair (angle $x$ seat configuration) evaluated

\begin{tabular}{|c|c|c|c|c|c|c|}
\hline \multicolumn{7}{|c|}{ Results of paired t test } \\
\hline \multicolumn{7}{|c|}{ Pairing between seats } \\
\hline Angles & $\mathrm{A} 0 \times \mathrm{A} 1$ & $\mathrm{~A} 0 \times \mathrm{A} 2$ & $\mathrm{~A} 0 \times \mathrm{A} 3$ & $\mathrm{~A} 1 \times \mathrm{A} 2$ & $\mathrm{~A} 1 \times \mathrm{A} 3$ & $\mathrm{~A} 2 \times \mathrm{A} 3$ \\
\hline MMY & 0.135 & $0.008^{*}$ & 0.147 & 0.454 & 0.615 & 0.221 \\
\hline GMY & 0.996 & 0.933 & 0.239 & 0.927 & 0.294 & 0.153 \\
\hline AAX & 0.098 & 0.601 & 0.222 & $0.006^{*}$ & 0.260 & $0.002^{* *}$ \\
\hline TTX & 0.279 & 0.336 & 0.417 & $0.042^{*}$ & 0.566 & $0.016^{* *}$ \\
\hline OT7Y & 0.852 & 0.300 & 0.532 & 0.270 & 0.529 & 0.500 \\
\hline T7T3Y & 0.215 & $0.010^{*}$ & 0.173 & $0.024^{*}$ & 0.771 & $0.036^{* *}$ \\
\hline C7T3Y & $0.0008^{* *}$ & 0.203 & 0.288 & $0.0008^{*}$ & $0.002^{*}$ & 0.716 \\
\hline OC7Y & 0.528 & 0.601 & $0.0004^{* *}$ & 0.100 & $0.00003^{* *}$ & $0.0001^{* *}$ \\
\hline MSMSX & 0.953 & 0.131 & 0.377 & $0.014^{*}$ & 0.170 & 0.200 \\
\hline ISISX & 0.130 & 0.159 & 0.431 & 0.749 & $0.004^{* *}$ & $0.007^{* *}$ \\
\hline LIRIX & $0.023^{* *}$ & $0.0008^{* *}$ & $0.003^{* *}$ & 0.389 & 0.569 & 0.758 \\
\hline
\end{tabular}

${ }^{*} \mathrm{H} 1$ - Higher than; ${ }^{* *} \mathrm{H} 1$ - Lower than greater than $\mathrm{A} 2$-indicating alignment after using the seat with different foam densities without adding EVA. According to this statistical analysis, seats $A 1$ and $A 3$ were not able to improve alignment with $\mathrm{A} 0$.

And on the pairing between the foam seat configurations, it is possible to highlight the $A 1 \times A 2$, because the result with the test with five angles indicated better alignment after the change from the single density seat (A1) to the $33 \mathrm{~kg} / \mathrm{m}^{3}$ density seat and $40 \mathrm{~kg} / \mathrm{m}^{3}$. However, for the $A 2 \times A 3$ pairing, the opposite occurred, since in five evaluated angles it was possible to observe that the $A 3$ promoted an increase in the angular values-which does not help the body symmetry of the sample.

The LIRIX angle showed lower values in the initial position (A0). This suggests that the placement of the foam seats intensified the pelvis asymmetry. Also, the individual descriptive analysis for this angle indicates that in $50 \%$ of the sample there was a decrease in the angular values of the LIRIX. This happened in at least one seat configuration when compared to the $\mathrm{A} 0$ situation. So, the paired $T$ test was performed again for this sample and the new results indicate a decrease in asymmetry with the use of the different foam seats in relation to the initial situation A0 (Table 3).

\section{Discussion}

The results regarding postural alignment in the initial situation (A0) indicate a significant misalignment of the angles evaluated. But other studies about postural symmetry in healthy individuals do not confirm the hypothesis of corporal symmetry as a standard of normality [23]. However, the study presented by [24] corroborates with the idea that the sitting posture of the individual with hemiplegia differs from that of healthy individuals. They used pressure mapping and found a weight symmetry index that was significantly divergent from the ideal symmetrical posture in the hemiplegic group and in the control group.

Also, the average value found for the LIRIX angle at the initial position $A 0\left(4.63^{\circ}\right)$ is different from that found in the study of Borello-France et al. [25]. They assessed this same angle with hemiplegic individuals sitting on a rigid seat and found a value of $2.1^{\circ}$ of lateral pelvic obliquity. Although they used a sample very similar to that of our study, some differences interfere with the results obtained. For example, their sample was evaluated in a wheelchair with a backrest. This interferes with the alignment and distribution of weight in posture, providing greater support and, consequently, greater stability in posture.
Table $3 p$ values for LIRIX angle $(n=9)$

\begin{tabular}{|c|c|c|c|c|c|c|}
\hline \multicolumn{7}{|c|}{ Result of paired $t$ test-LIRIX angle } \\
\hline \multicolumn{7}{|c|}{ Pairing between seats } \\
\hline Angle & $\mathrm{A} 0 \times \mathrm{A} 1$ & $\mathrm{~A} 0 \times \mathrm{A} 2$ & $\mathrm{~A} 0 \times \mathrm{A} 3$ & $\mathrm{~A} 1 \times \mathrm{A} 2$ & $\mathrm{~A} 1 \times \mathrm{A} 3$ & $\mathrm{~A} 2 \times \mathrm{A} 3$ \\
\hline LIRIX & $0.020^{*}$ & $0.010^{*}$ & $0.034^{*}$ & 0.577 & 0.789 & 0.542 \\
\hline
\end{tabular}

*H1-Higher than 
In addition, we observed that, for half of the sample, the replacement of the rigid seat base by the density foam of $33 \mathrm{~kg} / \mathrm{m}^{3}$ generated an increase in pelvic obliquity. However, although the more rigid base was better for the pelvic alignment of these individuals, it is not recommended to do so. Postural adequacy procedures must also consider patient comfort and the prevention of skin lesions $[5,26$, 27]. In summary, the statistical analysis of the LIRIX angle data indicates that $72 \%$ of the sample presented improvements in the pelvic alignment in at least one foam seat configuration-which directly reflected in the alignment of the upper trunk and head. These results are relevant because any pelvic alignment is clinically significant, as this is one of the main objectives of the rehabilitation process [25]. Thus, it is possible to conclude that the use of foam seats was beneficial for the postural alignment of the pelvis and was statistically significant. It is important to remark the effectiveness of the seat configuration with different foam densities without adding EVA.

Moreover, the placement of a foam of greater density under the hemibody that had greater weight discharge was effective in $78 \%$ of the sample. In this group, most had more benefits with the $A 2$ seat-containing foams with densities of $33 \mathrm{~kg} / \mathrm{m}^{3}$ and $40 \mathrm{~kg} / \mathrm{m} 3$. Thus, our initial hypothesis of this study was validated: we demonstrated that the use of seats with different foam densities was beneficial for postural alignment, but without the addition of EVA.

Furthermore, the indication of seats with different densities is commonly performed in clinical practice [3]. However, there is still no scientific evidence to support this conduct. In general, the densities of the foams for the seat are not specified by the therapists and users are only instructed to look for different densities for more comfort. Thus, the results of our study suggest that the use of densities of $33 \mathrm{~kg} / \mathrm{m}^{3}$ and $40 \mathrm{~kg} / \mathrm{m}^{3}$ are sufficient to promote better body alignment. In addition, these densities are easily found in the trade and the price is much lower than those of higher density. Also, the study of [28] showed that foams with higher densities $(50 \mathrm{~kg} / \mathrm{m} 3$ and $60 \mathrm{~kg} / \mathrm{m} 3)$ did not have the correct specifications with which they should have been manufactured.

For clinical practice, it is essential to identify postural asymmetries in hemiplegic individuals, since the entire functional prognosis of these patients depends on a gradual evolution of the range of movement, strength and postural alignment. And when asymmetries are not identified by visual and palpatory evaluations, they can cause losses in the performance of activities of daily living and complications such as chronic pain and installation of deformities. In this context, computerized photogrammetry can help in the initial assessment and periodic reevaluations of these individuals.
Also, the standardization of interventions for postural adequacy in a wheelchair is difficult and inadequate, because the individual needs and type of adaptation of each user are very specific. However, the establishment of some guidelines may be useful for the development of strategies for clinical practice and for other research in the area.

Finally, it is important to remember that this study was limited to evaluating only one of the aspects that interfere in the sitting posture of individuals with hemiplegia. So, it is necessary that other studies expand discussions in this area.

As future works, it is possible to conduct other studies regarding the sitting posture of hemiplegic individuals with new approaches: weight distributions, posture symmetry, pressure center changes and sensory-perceptual changes. Also, it is interesting to conduct an investigation of the effectiveness of seats of different densities fixed in the wheelchairs and evaluate their long-term use.

Funding This study was financed in part by the Coordenação de Aperfeiçoamento de Pessoal de Nível Superior - Brasil (CAPES); Finance Code 001.

Code availability Not applicable.

\section{Compliance with ethical standards}

Conflict of interest The authors declare that they have no conflict of interest.

Availability of data and material The data set supporting the conclusions of this article is included within the article.

Ethics approval This study was approved by the Research Ethics Committee of the Association for Assistance to Disabled Children (AADC) Protocol Number 01/2011.

\section{References}

1. Alm M, Gutierrez E, Hultling C, Saraste H (2003) Clinical evaluation of seating in person with complete thoracic spinal cord injury. Spinal Cord 41:563-571

2. Wallis SM (1995) The seating clinic. Curr Pediatr 5:165-179

3. Chaves ES, Rizo LR, Alegretti AL (2003) Adequação postural para o usuário de cadeira de rodas. In: Teixeira E, Sauron FN, Santos LSB, Oliveira MC (eds) Terapia Ocupacional na Reabilitação Física, 1st edn. São Paulo, Roca

4. Woodson AM (2008) Acidente vascular cerebral. In: Trombly CA, Rodomski MV (eds) Terapia ocupacional para disfunções físicas, 5th edn. São Paulo, Santos

5. Engström B (2011) Ergonomic seating: a true challenge: seating and mobility for the physically challenged risks \& possibilities when using wheelchairs. Posturalis Books, Sweden 
6. Genthon N, Vuillerme N, Monnet JP, Rougier P (2007) Biomechanical assessment of the sitting posture maintenance in patients with stroke. Clin Biomech 22:1024-1029

7. Pelmutter S, Lin F, Makhsous M (2010) Quantitative analysis of static sitting posture in chronic stroke. Gait Posture 32:53-56

8. Koo TKK, Mak AFT, Lee YL (1996) Posture effect on seating interface biomechanics: comparison between two seating cushions. Arch Phys Med Rhabil 77:40-47

9. Bolin I, Bodin P, Kreuter M (2000) Sitting position - posture and performance in C5-C6 tetraplegia. Spinal Cord 38:425-434

10. Ragan R, Kernozek TW, Bidar M, Matheson JW (2002) Seatinterface pressures on various thicknesses of foam wheelchair cushions: a finite modeling approach. Arch Phys Med Rhabil 83:872-975

11. Farley IV, Carvalho EMF, Barreto KML, Lessa FJD, Leite VMM (2003) What is the evidence for the effectiveness of postural management? Int J Ther Rehabil 10(10):445-449

12. McKenzie AM, Taylor NF (1997) can physiotherapists locate lumbar spinal levels by palpation? Physiotherapy 8(5):235-239

13. Harlick JC, Milosavljevic S, Milburn PD (2006) Palpation identification of spinous processes in the lumbar spine. Man Ther 12:56-62

14. Downey BJ, Taylor NF, Niere KR (1999) Manipulative physiotherapists can reliably palpate nominated lumbar spinal levels. Man Ther 4(3):151-156

15. Hominis D (2010) CorporisPro [Internet]. Data Hominis. Available from: http://www.datahominis.com.br/corporispro/. Accessed 4 Mar 2020

16. Pérez-Vicente S, Ruiz ME (2009) Descriptive statistics. Allergol Immunopathol (Madr) 37(6):312-320

17. Benjamini $Y$ (2012) Opening the box of a boxplot. Am Stat 4:257-262

18. Surhone LM, Timpledon MT, Marseken SF (2010) Shapiro-Wilk Test. VDM Publishing, Saarbrücken

19. Sheskin DJ (2011) Handbook of Parametric and Nonparametric Statistical Procedures, 5th edn. CRC Press, Florida
20. Box GEP, Cox DR (1964) An analysis of transformations. J R Stat Soc 2(26):211-264

21. Ross A, Willson VL (2017) Basic and advanced statistical tests: writing results sections and creating tables and figures. Sense Publishers, Rotterdam

22. Albuquerque SH (2003) Acidente vascular encefálico. In: Santos LSB, Oliveira MC (eds) Terapia ocupacional na Reabilitação Física, 1 st edn. São Paulo, Roca

23. Ferreira EAG, Duarte $M$, Maldonado EP, Burke TN, Marques AP (2010) Postural assessment software (PAS/SAPO): validation and reliability. Clinics 65(7):675-681

24. Au-Yeung SSY (2003) Does weight-shifting exercise improve postural symmetry in sitting in people with hemiplegia? Brain Inj 17(9):789-797

25. Borello-France DF, Burdett RG, Gee ZL (1988) Modification of sitting posture of patients with hemiplegia using seat boards and backboards. Phys Ther 68(1):67-71

26. Kim J, Mulholland SJ (1999) Seating/wheelchair technology in the developing world: need for a closer look. Technol Disabil 11:313-316

27. Cavalcanti A, Galvão C, Campor M (2007) Cadeira de rodas e sistema de adequação postural, In: Galvão C, Cavalcanti A, (Eds) Terapia Ocupacional: fundamentação e prática. Guanabara Koogan, pp. 25-33.

28. Silva FP, Beretta EM, Prestes RC, Kindlein W (2011) Design and milling manufacture of polyurethane custom. Aust Med J 4(9):500-506

Publisher's Note Springer Nature remains neutral with regard to jurisdictional claims in published maps and institutional affiliations. 